\title{
Research on location selection of super mall based on GIS Technology and Huff Model
}

\author{
Lei Zhou, Ye An \\ School of Business, Northeast Normal University, Changchun Jilin 130024, China
}

\begin{abstract}
This paper attempts to adopt GIS technology to select the best location for large-scale shopping malls in the region, and analyzes the various factors that should be considered in the location selection of large-scale shopping malls, including population density, traffic conditions and existing commercial areas and so on. Based on the detailed planning and field visit data collected in Changchun, Jilin Province, this paper has inputted the relevant data on the GIS platform to study such factors as population density, transportation convenience, existing competitors and then the alternative locations stand out. Huff model is employed to determine the best location among the alternative locations of shopping malls for the reference of the enterprises. The location selection of super malls is of strategic significance.
\end{abstract}

Key words: Location of super mall; GIS Platform; GIS; Huff model

Super malls stand as one of the important growth points of business. Recent years have seen super malls bear the burden from various sources, such as online retail and diversified consumer behaviour. Such being the case, the sales performance of super malls still attract the attention and praise. The location selection of super malls is the key factor influencing their survival, for the location chosen weigh heavily with the operating income and the scope of the commercial area. At the same time, the brand image in the customers' mind and even the development of the future business will suffer the impact.

In this paper, a clear and visualized method is used to decide the location. Several main factors, including population, transportation and commercial area, are selected and then are clearly presented on the GIS desktop platform in an intuitive layer format in the light of the land use planning within the region. According to the detailed planning of the region by the City Planning Department, combined with the population density distribution, the convenience of transportation and the existing competitors, the location strategy of the large integrated shopping mall in the Jingyue Development Zone is analyzed comprehensively.

\section{Review of research}

The researches of foreign scholars mainly focus on the local modification and optimization of the existing traditional models, and have not put forward a new method to guide the location selection; Some scholars collect specific data to verify the correlation between the relevant factors and location or measure the degree of impact on location without significant innovation. Suarez-Vega, Rafaelon and other scholars(2015) have improved the traditional Huff model. The traditional theory assumes that the sensitivity parameters of consumers to time or distance are constant. Considering the non-stationarity of the parameters in spatial distribution, Suarez-Vega and his partners used the least square method to perform local fitting in the study area. 
This algorithm makes the probability of the final calculation more accurate by avoiding a uniform sensitivity coefficient in the calculation of the model. The factors that affect the location of these supermarkets become the emphasis of researches performed by scholars, including Petra Olšová and Michaela Jánská (2016). Through the investigation of the existing shopping malls in St. Louis Lahm, the effects of these factors are verified by the method of correlation analysis.

Sun Haiyan (2017) and some others adopted analytic hierarchy process (AHP) to grade the alternative sites of large-scale shopping malls. Firstly, according to the principle of selecting the super mall, the factors to be considered are divided into several levels, and the hierarchical model is constructed. Then, according to the collected data, a contrast matrix is constructed, so that the weight of the data can be calculated, The consistency test also need to be completed. Finally ratings of locations of the alternative malls come into being. Ma Lina (2017) employed the expert opinion method to extract all kinds of factors that affect the location of large shopping malls. Considering the correlation between various factors, the D-S theory of artificial intelligence is introduced to deal with the above factors with a purpose to establish a model of location selection. The location of malls will be selected by solving the model. Fang Xia(2017) put the convenience of customers on the top of location, so she constructed the model of customer convenience. From three dimensions, including scales of super malls, traffic convenience and peripheral facilities, 260 consumers were investigated to determine each index and the weight of the index. The best location was selected after analyzing a region taken as an example. Domestic scholars have considered all kinds of factors in detail when studying the location problem. The majority of research perspectives are mostly from the shopping mall itself, while some others proceed from the perspective of customers. Taking into account the internal relation of various factors and the incompleteness of information, researches at home employ proper mathematical methods, which combine qualitative and quantitative factors well, so that valuable ideas and experiences are provided for further research.

Through the comprehensive study and collection of the literature, we find that when it comes to the location selection of shopping malls, scholars tend to use mathematical methods such as AHP to abstract and give weight to the factors that affect the location of large shopping malls, such as the population situation, infrastructure condition, land cost and competitive environment, and to come to the conclusion by building and then solving the model. However, the method is by no means intuitive.

Considering that decision-makers turn to a clear and visual method for location selection, the paper adopts the GIS desktop platform to analyze the population density, transportation convenience, competitors and other factors. After referring to the land planning situation in the region, the extracted indicators are presented clearly and intuitively on the platform by visual method. Taking the Jingyue Development Zone as an example, according to the Planning Department's detailed master planning of Jingyue Development Zone in Changchun City, combined with the factors of population density distribution, traffic convenience and existing competitors, this 
paper comprehensively analyzes the location strategy of large shopping malls in Jingyue Development Zone.

\section{Related theory}

(1) Central place theory

Central place theory, first created by Chris Taylor Christaller, introduce two basic concepts, the maximum range and the minimum demand respectively. The maximum range means the distance that the customer can accept when they go for a shopping, which reflects the radiation power of malls in the area. The minimum demand refers to the demand that allows stores to break even. Christaller believes that only when the maximum range is greater than the minimum demand, can shops continue to operate and avoid bankrupt. This theory, linking the scope of retail business with the behavior characteristics of consumers, has been continuously developed and perfected by scholars since then. Rose, who put forward the hierarchy theory, has introduced more factors which make the boundary of the business circle blurred and intertwined with each other.

(2) Regional interaction theory

The theory of regional interaction was first put forward by Relly, who studied 150 commercial districts and pointed out: if we select consumers in one region between the two regions, each possessing retail stores, as research objects, consumers will be attracted to the region closer to their region or the region with larger population. Future days witnessed that P.D.Convers has complemented Relly's law of retail attraction and proposed:

$$
D_{a b}=\frac{d}{1+\sqrt{P_{b} / P_{a}}}
$$

(formula 2.1)

Note: $D_{a b}$ indicates the scope of the business district in the area $a ; P_{a}$ the number of people in the area $a ; P_{b}$ the number of people in the area $b ; d$ the distance between the area $a$ and the area $b$.

There are few factors involved in this model. With the continuous development of society, the convenience of transportation is greatly enhanced, which is not the main factor to determine the consumption of customers in stores. In view of this, Black, one of scholars in the field, put forward the theory of multiple factors on the basis of the above models and incorporated size, image and service of stores and other factors into the model.

(3) Saturation theory

The saturation theory is proposed by Saul Cohen and his partners to measure whether the number of retailers in a business district can meet the needs of consumers in that area. The following formula is expressed in terms of the saturation index of the business circle: 


$$
I R S=\frac{(C) \times(R E)}{R F}
$$

(formula 2.2)

Note: $I R S$ indicates the saturation index of a business circle in the region; $C_{\text {the number of }}$ potential consumers in the region; $R E$ the average consumption level of these consumers; $R F$ the total operating area of the retail stores in the region.

When the value of IRS is too high, it means that the number of stores in a certain area is just enough to meet the needs of the local consumers, or that the supply exceeds the demand of the consumers, which means that the business area is saturated or supersaturated. We can predicted that there is no potential market opportunity in the region, which is detrimental to the competitors ready to enter the market. In contrast, there exist potential opportunity for other players to gain share in the market of the region.

(4) GIS technology

Geographic Information system (GIS) can be traced back to the 1960s. Its main function modules include spatial data input, statistical analysis and visual output of analysis results. It is the result of the combination of traditional geography science and modern computer. In the last ten years, GIS has grown into a comprehensive application tool.

In the past, it was mainly applied in geography, transportation, telecommunications, mining and other fields. The booming development of commerce in recent years bring about the commercial GIS. We can use software to analyze and solve many problems, such as identifying current and potential customer base, estimating sales volume and delineate sales area, calibrating undeveloped sales market, identifying competitive areas now and in the future, evaluating areas that form competitive situation, optimizing sales channel of the product and evaluate the performance, providing evidence for adjusting business strategy and further expansion or contraction strategy on the basis of analysis of the change of sales level in different regions.

By using this technology to select the location of the mall, the present situation of the influencing factors, such as population density, traffic information and competitors, can be displayed intuitively in the workspace, which is convenient for decision makers to pinpoint instantly the geographical location that can be made use of. It makes up for the deficiency of traditional methods in spatial information management and analysis.

\section{The main factors affecting the location of super malls}

\section{(1) Population status}

One of the criteria for selecting the location of a super mall is to be near a residential area, which stands as the reason why many malls gain chance to develop. According to the relevant documents, whether a mall makes money or not is mainly determined by whether there exists a customer group enjoying luxury consumption within the area 1600 meters away from the mall.

1)Population size: Whether there exists a considerable population around the mall has a significant impact on business performance. 
2)Population density: Population density is usually measured by the number of people or households in the same area.

3) Income of residents: The income level of the residents is an important factor affecting their consumption ability, which indirectly affects the upper limit of the sales volume in the region and will have a significant impact on the future operation of the shopping mall.

4) Family structure: The demographic composition of a family presents different characteristics.

5) Demographic structure: That the population in the region is dominated by the elderly or the young, the sex ratio, the occupation situation and the level of education also affect the location decision.

(2) traffic conditions

There is a negative correlation between the number of customers going shopping in the mall and the distance from the mall. Therefore, the traffic conditions should be taken into consideration in the decision-making, including the connection between the mall and various transportation channels such as highways, subway and the like .

1)Transport convenience: Whether the transportation is convenient or not directly affects the time cost of shopping and the frequency of the customers visiting the shop.

2) Urban planning: Location decision, a long-term and far-reaching decision, will face failure if the long-term urban construction planning can not be grasped well.

(3) The existing business district.

The competitors around the mall will have a significant impact on its performance. Therefore, competitors should be fully considered in the selection of the site. Only by knowing the direct and indirect competitors comprehensively, it is possible to establish a competitive advantage and gain a foothold in the region.

1)Saturation. The level of demand within a region is stable for a certain period of time. If supply capacity of the existing mall is basically enough to meet or exceed the level of consumer demand in this area, new malls are not suitable for admission.

2) Difference. Generally speaking, if there is no difference in the proportion of all kinds of goods, the price and the customer experience compared with other malls in the region, it is easy to fall into the plight of homogeneous competition.

3) The ability of competitors. Work is to be done in terms of examining the types of goods and services provided to consumers by similar malls in the region, their market share and marketing strategies, current and future business strategies, commodity structure, management characteristics and management level.

\section{Empirical Analysis on location of Large-Scale Mall based on GIS platform}

According to the detailed master planning map of Jingyue Development Zone in Changchun city, we extract and sort out the relevant data and information of this area. The GIS platform developed by the Supergraph Company is deployed to vectorize the planning base map, and all kinds of information are inputted to the platform for subsequent analysis. The land types in this area are: residential land, commercial and residential mixed land, finance and insurance land, refueling station land, cultural 
activity land, fire protection land, social welfare land, university land and so on. Among these different lands, commercial land, retail commercial land, mixed commercial land and commercial and residential mixed land embrace possibility to be included in the list for the location selection of super malls. The detailed master planning map is imported into the workspace as a collection, and the planning map is vectorized in the GIS workspace, according to the partition of plots and different functions. Moreover, the land area shall be vectorized and the "use" property field be created.

The population information of each land block shall be inputted into the property field of the land block of the residential area According to the detailed master planning map of Jingyue Development Zone, the road network of this area is drawn on the GIS software platform. At the same time, by inputting each bus stop one by one to the platform and investigating the number of bus lines passed through each bus stop, we have reason to assume that a bus stop equipped with more bus lines is more convenient for consumers. This is why we take the number of buses as the weight of the bus stop and create a new weight field in ways that to calculate the accessibility coefficient of a certain point. This paper is mainly based on the upper limit of residential units in the residential area of the detailed master planning, which is approximately regarded as the distribution of population density. It is believed that if two areas possess the same floor space, the greater the number of homes in an area, the greater the population density of the area. Given that the data interpolation algorithm would be used later,the data conversion function in GIS shall be applied on the basis of surface data in ways that the data form of residential plot is converted into point data while the property field remains unchanged. The converted population center is located in the center of the original land block, and the denser the red dot is, the larger the population is.

(1) Regional spatial distribution of population density

Regarding the distribution of population density in this region, we can conclude that the population density of a certain block decreases as the distance away from the region increases, so the farther away from the region, the smaller the weight will be given. Based on this, we select inverse Distance to a power interpolation method among many a interpolation method provided by GIS statistical analysis module. The algorithm can generate continuous smooth parameters that decrease with the increase of distance and interpolate isolated population density points of each plot constantly. Based on the distribution of population density in the region, five of the most densely populated areas were first selected, with the red spots located in the most densely populated areas, as shown in figure 4-1: 


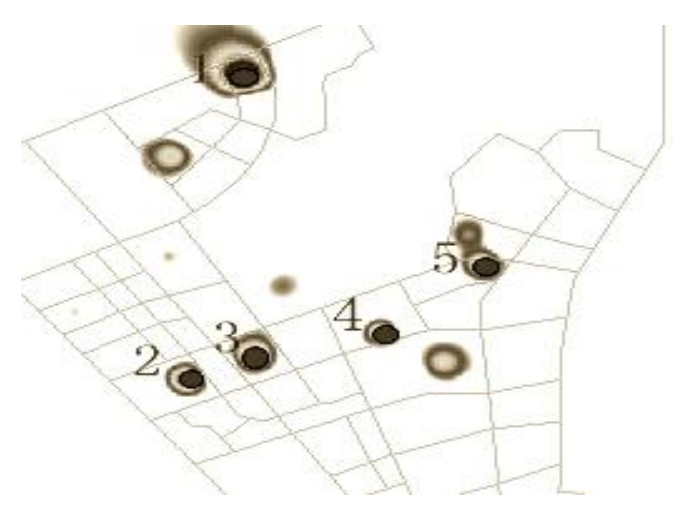

Fig.4-1 Alternative point distribution diagram

In this paper, the five most densely populated spots are regarded as alternative sites for super malls, but the final location may not necessarily fall on these five points. Because of the impact of land-use planning and other influencing factors, it may eventually adjust the five options to conform to the planning of the region.

(2) Regional bus accessibility

For the accessibility of public transportation, this paper adopts Buffer method, which can be implemented in buffer analysis module of GIS platform. That is, for a series of objects, which may be points, lines or surfaces, the parameters are set according to the pre-calculated buffer distance, and the system generates buffer regions around the objects.

The buffer distance set in this paper stands as 1200 meters, the number selected from two perspectives: on the one hand, the alternative point is the most densely populated location, and the final location may be adjusted according to land use planning and other factors. According to the study focusing on consumer behavior, 500-meter walking distance from the mall is acceptable to consumers, so the flow of customers will still be the same when the final location is moved within 500 meters; on the other hand, the maximum distance to the bus station in consumers' hearts falls on around 500 meters. Therefore, considering the above two reasons, we set 1200 meters as the buffer distance, and then extract stations within this range.

For a specific station among 5 stations within the alternative buffer zone, the accessibility is positively correlated with the number of buses passing through the stop, and negatively correlated with the distance from the stop to the alternative point. The formula is as follows:

$$
r=\sum_{i=1}^{n} W_{i} / S_{i}
$$

(formula 4-1)

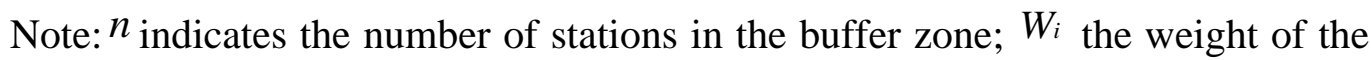
stops ( determined by the number of bus lines passing through the stop and more details in Appendix 2); $S_{i} \quad$ the distance between stop and alternative point 
(meters) generated by the length property field of road network; $r$ bus accessibility coefficient of alternative points. As shown in table 5-1:

Tab.4-1 Bus Accessibility coefficient of alternative point

\begin{tabular}{|c|c|c|c|c|c|}
\hline $\begin{array}{c}\text { Alternative } \\
\text { point }\end{array}$ & 1 & 2 & 3 & 4 & 5 \\
\hline $\begin{array}{c}\text { Accessibility } \\
\text { coefficient } \\
(\%)\end{array}$ & 76.1 & 82.7 & 79.5 & 72.4 & 74.2 \\
\hline
\end{tabular}

(3) Existing business circles in the research area

At present, there are large business circles in the region, that is, Xunchi Square, International Convention and Exhibition Center, Fudi Carnival Square, as shown in the rectangular region. The existing competitors generate a buffer area of 1200 meters, and then overlap the 1200-meter radiation area of the alternative point with the 1200-meter radiation area of the current super mall. The results of buffer analysis are shown in the figure:

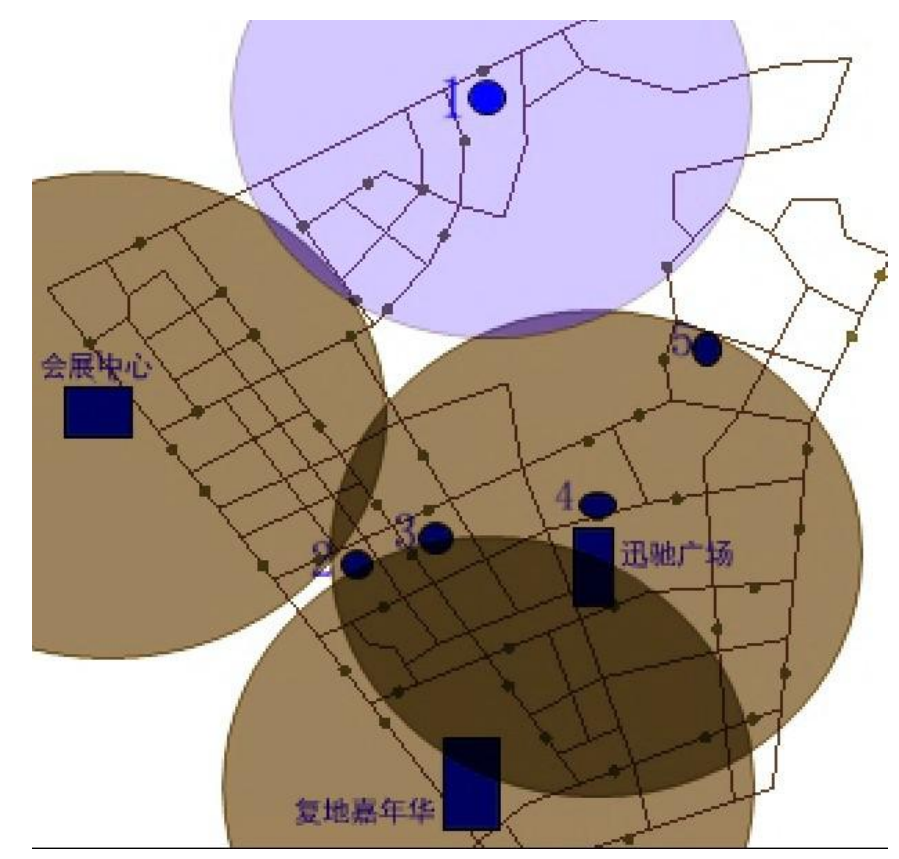

Fig.4-2 Buffer analysis

The gray area in the picture is the radiation range of the existing super malls. It can be seen intuitively that the commercial competition in the Jinyue Development Zone show extremely fierce, and the existing large-scale shopping malls basically cover most of the areas.

(4) Preliminary determination of alternative addresses for super malls

As shown in figure 4-2, alternative points 3 and 4 coincide with the buffer zone of Xunchi Square. There exists no super mall in the 1200-meter buffer zone of alternative point 1 , and points 5 and 2 are located on the radiation boundary of Xunchi Square. The five points are analyzed one by one as follows:

1) For there is no super mall in the 1200 -meter radiation area of point 1 , so point 1 should be considered; 
2) While points 2 is located on the radiation boundary of Xunchi Square, it still can be listed in the options. A glance of the planning map can tell us point 2 is in the middle of Xunchi Square, International Convention and Exhibition Center, Fudi Carnival Square, three of which stand as the main underpinning for local consumers. According to the saturation theory, it can be considered that the supply of this position is greater than the demand, so it is not suitable to open new shopping malls; and although Carnival Square and International Convention and Exhibition Center temporarily lag behind the Xunchi Square and lack robust development for the time being, it will be very detrimental to the survival of the mall facing fierce competition in the future if the commercial district adjusts its business strategy in the later stage to attract more consumers. An all-round consideration helps us exclude point 2.

3) Point 3 shall be abandoned given that it coincides with the buffer zone of the Xunchi Square;

4) Point 4 shall be abandoned given that it coincides with the buffer zone of the Xunchi Square;

5) While points 5 is located on the radiation boundary of Xunchi Square, it still can be listed in the options.

Combining the results of the above studies on population density, transportation convenience, and commercial competitors, we can eliminate alternative points 2, 3, 4 and keep alternative points 1 and 5 .

(5) Determine the best location for super malls

Huff, one retail scientist, has studied the factors that determine the attractiveness of retail stores to customers. Huff model was put forward around 1960. He believed that the probability of customer going to a business district in a certain area embracing more than one business district is determined by the scale of the business district and the distance between the customer and the business district. As follows:

$$
P_{i j}=\frac{S_{j} / T_{i j} b}{\sum S_{j} / T_{i j} b}
$$

(formula 4.2)

Note: $P^{i j}$ indicates the probability of the customers in the area ${ }^{i}$ going to the retail store; $S_{j}$ the size or the area of the store; ${ }^{T_{i j}}$ the distance from the customer in the area $i$ to the retail store; $b$ the sensitivity parameters of the customers to the distance obtained through field surveys or mathematical means; $S_{j} / T_{i j} b_{\text {the retail store }}{ }^{j}$ s attractiveness to the customers in the area $i ; S_{j} / T_{i j} b$ the total attraction of all the retail stores in the region.

Here we assume that the future size of malls are the same. Such being the case, the probability of consumers going shopping depends mainly on the distance to the mall. The bus accessibility is measured in this paper. According to the calculation results, the bus accessibility of alternative point 1 is better than that of point 5 . 
Beyond that, there boasts a lot of bus routes from this point 5 to Xunchi Square while point 5 is not in the radiation area of Xunchi Plaza, which is obviously not conducive to the arrival of the new shopping mall. According to the actual situation in this region, the buffer zone of point 1 has some part of radiation area of Jingyue Development Zone. However, the above two factors point to the promising advantage if the point 1 is selected as the final location.

To sum up, point 1 can be regarded as the best location for super malls in Jingyue Development Zone. In this paper, the author tried to use GIS technology to analyze and make decisions in order to select the location of large shopping malls. And combined with the actual situation of the region, objective discussion has been presented. In the process of reaching the final conclusion, in addition to quantitative analysis, it also combines the intuitive judgment obtained from field visits with a purpose to build decision-making on the reality. GIS boasts as a kind of modern comprehensive application technology, which can carry out spatial analysis efficiently and intuitively. It is an effective tool for location selection of large shopping malls. Through a series of analysis in this paper, the conclusion is basically in line with the existing competition pattern and the selected site also accord with the intuitionistic and empirical judgment, which fully demonstrate the effectiveness of the GIS.

\section{References:}

[1]Fang Xia. Based on consumer convenience shopping location study [D]. Zhejiang Gongshang University, 2017.

[2]Lu-Tao WANG,Ye-Yun LIU. Research on Location Based on Gravity Method of Changsha City Greenery Fruit Supermarket Chain Distribution Center[P]. DEStech Transactions on Economics, Business and Management,2017.

[3]Petra Olšová,Michaela Jánská. Location of super and hypermarkets in the city of Ústí nad Labem[J]. GeoScape,2016,10(1).

[4]Sun Dan, Zhou Lisa. Based on the theory of business circle, the location of Zhabei store in Shanghai's RF mart, [J]., China management informatization, 2015,18 (10): 144-145.

[5]Jiang Chongyang. Spatial layout and optimization of large shopping malls in Changsha [D]. Central South University of Forestry and Technology, 2015.

[6]Liu Hongjian, Wang Wei, Luo Haijun, Xiao Weihong. Based on the combination of spatial syntax and analytic hierarchy process (AHP), the location method of shopping malls is studied [J]. surveying and mapping technology and equipment, 2014,16 (03): 17-20.

[7]Wang Lingyun. Study on the factors affecting the location of large shopping malls [D]. Zhejiang University of Technology, 2012.

[8]Thiel, D.,Hovelaque, V.,Duc Ngo Pham. A multi-agent model for optimizing supermarkets location in emerging countries[P]. 2012.

[9] Li Zhaojun. Research on the location of Guangzhou large shopping mall based on Geostatistics [A]. China Statistical Education Institute.2015 (fourth) National College Students statistical modeling contest paper [C]. China Statistical Education Institute: 2015:30.

[10] Li Weicai, Zhao Liqin, Xiao Lihua. Application of fuzzy decision making in the evaluation of the location of large shopping arcade [J]. Jiangxi science, 2015,33 (02): 151-155. 